A.J.E. Dirkzwager, I. Bramsen, H.M. van der Ploeg

Factors associated with posttraumatic stress among peacekeeping soldiers.

Anxiety, Stress and Coping: jrg. 18, 2005, nr. 1, p. 37-51

\begin{tabular}{|l|l|}
\hline Postprint Version & 1.0 \\
\hline Journal website & $\underline{\underline{\text { http://journalsonline.tandf.co.uk/(qttvtx455uv24vracsibqi45)/app/home/con }}}$ \\
\hline $\begin{array}{l}\text { tribution.asp?referrer=parent\&backto=issue,3,5;journal,8,20;linkingpublica } \\
\text { tionresults,1:300193,1 }\end{array}$ \\
\hline Pubmed link & - \\
\hline DOI & $10.1080 / 10615800412336418$ \\
\hline
\end{tabular}

VU University Medical Center, Department of Medical Psychology, Amsterdam, The Netherlands

Correspondence: A. J. E. Dirkzwager, Department of Medical Psychology, VU University Medical Center, Van der Boechorststraat 7, 1081 BTAmsterdam, The Netherlands. Tel: +31-20-4448220. Fax:+31-20-4448230. E-mail: anja_dirkzwager@hotmail.com

\title{
Factors associated with posttraumatic stress among peacekeeping soldiers
}

\author{
A. J. E. DIRKZWAGER, I. BRAMSEN, \& H. M. VAN DER PLOEG
}

\begin{abstract}
This study aimed to investigate positive and negative consequences of peacekeeping operations, help-seeking behaviour among peacekeepers, PTSD prevalence rates and factors associated with PTSD symptoms. A sample of 3,481 peacekeeping soldiers who participated in various peacekeeping operations was investigated on average 6 years following their deployment. The prevalence of PTSD was $5.6 \%$ overall, with $8.0 \%$ among peacekeepers of the former Yugoslavia and $3.7 \%$ among peacekeepers who went to Cambodia. Twelve percent received professional help during deployment.

The majority reported positive consequences of the deployment as well (e.g., a broadening of their horizon [82\%], increased self-confidence [52\%]). The following variables were significantly associated with current PTSD symptoms: lower level of education, being single, more traumatic situations during deployment, feeling more powerless and threatened, the idea that the mission had become meaningless, having had no control over the situation, and the use of professional help during deployment.
\end{abstract}

Many countries from all over the world have been involved in international peacekeeping operations since 1948 (Liu, 1992). Although peacekeeping operations are frequently associated with a lower stressor intensity than combat situations like World War II and the Vietnam War, peacekeeping personnel are also subjected to stressful situations (Litz, 1996).

During deployment peacekeeping soldiers may be exposed to life-threatening situations like shootings, being taken hostage, and hostile reactions of the conflicting parties. In addition, peacekeepers are increasingly providing humanitarian aid and may witness human distress, such as starving, sick or wounded people. Meanwhile the principle of non-use of force except for self-defense is central to the concept of UN peacekeeping. Personnel involved in peacekeeping operations must often be able to restrain their reactions and to control both fight and flight impulses, even while being exposed to (life)-threatening situations. In addition, it is important that they maintain their neutral role. Thus, peacekeeping operations may make great demands upon peacekeepers and may saddle them with new stressors.

Exposure to traumatic situations can result in psychological and physical adjustment problems. In the field of trauma research, the diagnosis of posttraumatic stress disorder (PTSD) or the severity of PTSD symptoms is used as an indication for a stress reaction after exposure to a traumatic situation (American Psychiatric Association, 1994). Research on the stress reactions among veterans ofWorldWar II and the VietnamWar has shown that a number of veterans may experience psychological adjustment problems, even long after the war has ended (Bramsen, 1995; Bramsen \& Van der Ploeg, 1999a; Clipp \& Elder, 1996; Kulka et al., 1990; Zatzick et al., 1997). 
In recent years, researchers have become increasingly interested in the health consequences of participation in peacekeeping operations. Studies among peacekeeping personnel have shown that although most people adjust well following deployment, a significant group may develop symptoms of PTSD. PTSD prevalence rates among peacekeeping personnel appear to vary. For instance, MacDonald and colleagues found that only $1 \%$ of New Zealand peacekeeping personnel reported PTSD (MacDonald, Chamberlain, Long, \& Mirfin, 1996). Among Norwegian peacekeepers who participated in the peacekeeping operation in Lebanon, and were investigated on average 6.6 years after their service, the prevalence of PTSD was 5\% (Mehlum \& Weisaeth, 2002). Litz et al. (1997) found that $8 \%$ of a sample of active duty personnel deployed to Somalia met the criteria for PTSD in a study conducted on average 5 months after return to the United States (Litz, Orsillo, Friedman, Ehlich, $\&$ Batres, 1997). In a sample of Australian veterans who went to Somalia about one-fifth reported traumatic stress 15 months after their return (Ward, 1997).

It is clear that not every peacekeeper develops PTSD following exposure to war-zone stressful situations. An intriguing question still remains why some people develop PTSD (symptoms) while others do not. Identification of risk factors for PTSD symptomatology is important for improving our knowledge regarding prevention and treatment of PTSD.

Research on risk factors for PTSD symptoms among combat veterans has demonstrated that a higher level of exposure to stressful war events is associated with more PTSD problems (Bramsen, 1995; Friedman, Schnurr, \& McDonagh-Coyle, 1994; Kulka et al., 1990; Litz et al., 1997). Besides exposure-related factors, certain demographic and personal characteristics (e.g., younger age, lower level of education, minority ethnicity, prior psychiatric disorder, the way a person copes with stressful events), and environmental factors (such as the degree and quality of social support surrounding the person) appear to be associated with PTSD symptom severity among veterans (Green, Grace, Lindy, Gleser, \& Leonard, 1990; Kulka et al., 1990; Solomon, Mikulincer, \& Avitzur, 1988; Solomon, Mikulincer, \& Flum, 1988; Wolfe et al., 1993). Compared with studies among other military populations, studies investigating factors associated with PTSD among peacekeeping personnel have mainly focused on exposure-related and personal factors, and found similar risk factors (Bache \& Hommelgaard, 1994; Kettner, 1972; Litz et al., 1997; Sutker et al., 1993; Wolfe et al., 1993). However, to date, the number of studies investigating risk factors for PTSD among peacekeeping personnel is still limited.

In the present study we were also interested in the more subjective perceptions of the deployment period. This is in line with the ideas of Lazarus and Folkman, who argued that instead of a solely stimulus approach, which defines stress as the result of an environmental stimulus, it is the meaning constructed by a person about what is happening that is crucial to the arousal of stress reactions. Their theory identifies two processes, cognitive appraisal and coping, as critical mediators of stressful person_environment relations and their outcomes (Lazarus, 1999; Folkman, Lazarus, Dunkel-Schetter, Delongis, \& Gruen, 1986).

Therefore, in addition to objective traumatic situations during deployment (such as being held hostage or being shot at), more subjective appraisals of the deployment period (e.g., the degree persons evaluated the deployment as threatening or feelings of powerlessness) may also be of importance.

In addition to negative effects, traumatic events can also result in positive effects. Studies that have examined the benefits people perceive as resulting from stressful events demonstrated that three consistent domains of positive changes have appeared: (1) selfconcept (e.g., perceiving oneself as a stronger, more mature, or more competent person), (2) relationships with social networks (e.g., perception of improved social relations), and (3) perception of personal growth and life priorities (Updegraff \& Taylor, 2000).

Although most studies on peacekeeping personnel focused on negative outcomes of being deployed, a few studies have examined potential benefits of participation in peacekeeping missions. For instance, a study among Norwegian soldiers who participated in the peacekeeping operation in Lebanon showed that a majority of the soldiers reported that their deployment experience had increased their selfconfidence, expanded their political understanding, increased their stress tolerance, and improved their military qualifications (Mehlum, 1995). Consistently, in a study among Danish UN soldiers, the majority of the soldiers reported that their self-confidence had increased and that they were better able to master stressing situations after their deployment experience (Bache \& Hommelgaard, 1994). So, in 
addition to negative consequences following peacekeeping operations, peacekeepers can also emerge from missions with positive consequences. In the present study attention was paid to both negative and positive consequences of the deployment period.

It is conceivable that veterans experiencing severe adjustment problems may need and benefit from health care services. Previous studies have shown, however, that certainly not all war veterans with problems seek professional help. For instance, in the National Vietnam Veterans Readjustment Study, $78 \%$ of the veterans with a current PTSD did not currently receive mental health care services, while $38 \%$ of them never did so (Kulka et al., 1990). In addition, a study among World War II survivors showed that $59 \%$ of the highly exposed respondents with a current PTSD did not seek professional help in the 3 years preceding the study (Bramsen \& Van der Ploeg, 1999b). Until now, information on help-seeking behaviour among peacekeeping soldiers for complaints related to their deployment experiences is very scarce. More knowledge about the number of peacekeepers using professional health care can result in a better adjustment of health care organizations to the needs of peacekeepers, and can be important for policymakers. Especially, more knowledge about the relationship between the use of professional help at an early moment and the development of PTSD at a later moment may be helpful in identifying persons at risk. For instance, it could be hypothesized that those using professional help during deployment are at increased risk for later PTSD symptoms since they were already experiencing problems during their deployment. On the other hand, having had professional help during deployment may have decreased the risk of subsequent PTSD symptoms because they received professional help at an early moment.

The aims of the present study are to examine positive and negative consequences of peacekeeping operations, PTSD prevalence rates, help-seeking behaviour, and factors associated with current PTSD symptoms among a large sample of peacekeeping soldiers.

These issues are analyzed according to the countries of peacekeeping mission (Lebanon, former Yugoslavia, and Cambodia). The following research questions are addressed: (1) What positive and negative experiences of being deployed do peacekeepers report?; (2) What prevalence rates of PTSD are found among peacekeeping soldiers?; (3) How many peacekeeping soldiers report that they have contacted health care professionals during deployment for problems they attribute to their peacekeeping experience?; and (4) What factors are associated with current PTSD symptoms? We examined the following factors: demographic characteristics, the number of traumatic situations during deployment, the subjective appraisal of the deployment period, and help-seeking behaviour during deployment.

\section{METHOD}

\section{Participants}

A questionnaire was sent to a sample of 8,042 veterans, i.e., those peacekeepers who had left military service and who had participated in international peacekeeping operations since 1975 . This sample consisted of (1) all veterans of the Royal Netherlands Air Force (502) and the Royal Netherlands Navy $(1,735)$ who participated in peacekeeping operations since 1975, (2) all veterans of the Royal Netherlands Army $(4,064)$ who participated in peacekeeping operations since 1990, and (3) a random sample of 1,741 veterans of all veterans who participated in the peacekeeping operation UNIFIL in Lebanon. A total of 3,481 veterans returned the completed questionnaire, resulting in a response rate of $43 \%$.

Most of the veterans were male (98\%), and ranged in age from 19 to 73 years, with a mean age of 31 years $(\mathrm{SD}=9.0)$. The majority of the subjects were married or cohabiting $(59 \%)$. Most veterans had a lower $(39 \%)$ or middle (44\%) education, $13 \%$ finished a higher educational level. Three major categories of peacekeeping operations emerged: veterans who went to the former Yugoslavia in the years 1992_1996 $(N=1,367 ; 39 \%)$, veterans who served in Lebanon between 1979 and $1986(N=$ $883 ; 25 \%)$ and veterans who participated in the operation in Cambodia between 1992_1994 $(N=305$; $9 \%)$.

Therefore, we were able to make a comparison between veterans of these three peacekeeping operations. Investigating the Lebanon peacekeepers will provide information on PTSD rates and risk factors among peacekeepers of operations that took place a long time ago, while investigating peacekeepers of the former Yugoslavia and Cambodia will provide information on PTSD 
symptomatology among peacekeepers of more recent operations. The other operations, labeled as

"Various missions" $(N=926 ; 27 \%)$, is a heterogeneous group and consists of a variety of peacekeeping operations, such as missions in the Persian Gulf and Gulf of Oman (8\%), the Multinational Force and Observers (MFO) in the Sinai (5\%), operations in the Adriatic Sea (4\%), the Gulf War (3\%), operation Deny Flight in Italy (2\%), United Nations Truce Supervision Organization in the Middle East (UNTSO; 1\%), and operations in Africa (e.g., UNAVEM, UNAMIR, UNOMOR; $1 \%)$.

On average the former peacekeepers served 5.6 months abroad $(\mathrm{SD}=2.6)$. For the majority of the peacekeepers $(92 \%)$ it was their first deployment, $8 \%$ had participated in at least one or more previous deployments. The former peacekeepers were studied on average 6.1 years following their deployment (SD_5.4). The period between the end of deployment and the present study ranged from less than one year to 21 years.

\section{MEASURES}

Demographic and military characteristics. Questions concerning: gender, age, education, and marital status were included in the questionnaire. Military characteristics, i.e., military rank and number of years elapsed since deployment were included as well.

Help-seeking behaviour. One question asked the peacekeepers whether they had contacted a professional health care worker (i.e., one or more sessions) during their deployment (answer categories were "yes" or "no").

Exposure to traumatic war zone situations. A list of 13 items referring to potentially traumatic situations during deployment was presented. Items referred to war situations, such as whether the subject experienced shootings directed at other people and/or at himself, whether the person was held at gunpoint, was held hostage, or witnessed dead/wounded people. Also potentially traumatic situations associated with peacekeeping operations were included, like witnessing human distress and rejection by the local population. Answer categories were "yes" or "no". A summary score counted the number of situations reported. Cronbach's $\alpha$ coefficient for the scale was 0.80 . The scale has an adequate test - retest reliability of 0.72 (Bramsen, Dirkzwager, Van Esch, \& Van der Ploeg, 2001).

Appraisal of deployment. Three dichotomous items referred to the more subjective perception of the deployment: having had no control over the situation, having the idea that the mission had become meaningless, and having had insufficient possibilities to intervene. Two additional questions were used to further measure the appraisal of the deployment. These questions referred to the degree in which subjects rated the deployment period as threatening and the degree to which they had experienced feelings of powerlessness during deployment. A five-point Likert scale was used $(1=$ not at all, $5=$ extremely).

Positive and negative experiences. Nine dichotomous items were included to inquire how the peacekeepers judged their deployment period. Items referred to both positive and negative judgements, such as "judging the deployment period as": an experience that broadened my horizon, a period characterised by comradeship, an experience that increased my selfconfidence, a period of heavy burden for my home front, a period not yet completely dealt with, or an experience that did more bad than good. Respondents were instructed to mark the items that applied to them.

PTSD. To measure current PTSD symptoms the Self-Rating Inventory for PTSD (SRIP) was used (Hovens, Bramsen, \& Van der Ploeg, 2000; Hovens et al., 1994). The SRIP consists of three subscales corresponding to the three symptom clusters of the DSM-IV: Intrusion (six items), Avoidance (nine items) and Hyperarousal (seven items). Some DSMIV items are not formulated in a completely unambiguous way. In the SRIP all items are.

Thus, in the SRIP, items such as "difficulty falling or staying asleep" were expressed as two specific items: "difficulty falling asleep" and "difficulty staying asleep". In this way 22 items were used to represent the original 17 DSM-IV items. A four-point Likert scale was used to measure the severity of each symptom (1_not at all; 4_a great deal). 
The SRIP has proven to be reliable and valid (Hovens et al., 1994). Test_retest reliability correlation coefficient was 0.92 , and the internal consistency had an $\alpha$ coefficient of 0.92 .

The scale correlated significantly with the Clinician Administered PTSD Scale (CAPS), the Mississippi Scale for Combat-related PTSD, the MMPI PTSD subscale and the Impact of Event Scale. Sensitivity and specificity of the SRIP in relation to the CAPS were found to be very good (sensitivity, $85 \%$; specificity, 70\%) (Hovens et al., 1994). Cronbach's $\alpha$ coefficient for the total scale was 0.94 in this study. Cronbachs $\alpha$ values for the subscales ranged from 0.85 (Hyperarousal) to 0.88 (Avoidance). PTSD diagnosis was determined according to the DSM-IV rules: a person had to report score of "quite a bit" or "a great deal" on at least one item of Criterion B (Intrusion), on at least three items of Criterion C (Avoidance), and on at least two items of Criterion D (Hyperarousal).

\section{Procedure}

In 1996, the veterans received a questionnaire, a letter explaining the purpose of the study, and a prepaid envelope. To protect the privacy of the veterans the questionnaire was sent to them by their former branch of military service. The completed questionnaire could be returned using the prepaid envelope, thereby giving informed consent. In accordance with Dutch law, a detailed set of rules and regulations to protect the privacy of the respondents was followed, which had been approved by the Dutch Data Protection Authority.

\section{Data analyses}

Chi-square tests were used to examine differences between peacekeeping operations in PTSD rates, positive and negative experiences, and help-seeking behaviour. Analyses of variance were used to explore differences between peacekeeping operations in the mean scores of PTSD symptoms, the number of traumatic situations during deployment, and the appraisal variables.

Hierarchical multiple regression analyses were used to examine the contribution of demographic and military characteristics, the number of potentially traumatic situations during deployment, the appraisal variables, and help-seeking behaviour during deployment to the variance of current PTSD symptoms. This analysis was done for the total group of peacekeepers and for the three major peacekeeping operations separately. Since the "Various missions"' group was a heterogeneous group, we did not perform the regression analyses for this group separately. Demographic and military characteristics were entered in the first step, followed by the number of potentially traumatic situations during deployment and the appraisal variables in the second and third step. Help-seeking behaviour during deployment was entered in the last step. In this way the contribution of the appraisal variables and help-seeking behaviour could be determined after demographic characteristics and the number of potentially traumatic situations during deployment were controlled for.

\section{RESULTS}

\section{Exposure characteristics}

On average the peacekeepers reported that they had experienced 4.4 potentially traumatic situations during deployment $(\mathrm{SD}=3.0)$ (See Table I). Veterans from the peacekeeping operations differed significantly with respect to the mean number of traumatic situations during deployment and the appraisal of the deployment. Post hoc (Scheffe) tests showed that veterans who served in Cambodia reported on average more potentially traumatic situations than both peacekeepers from the former Yugoslavia and Lebanon. Veterans who went to the former Yugoslavia reported on average more feelings of powerlessness than veterans from Cambodia did. Veterans from the "Various missions" group scored lower on the exposure variables than veterans from the former Yugoslavia, Lebanon and Cambodia did. For the group as a whole the most frequently reported stressful situations were: shootings not directed at one-self $(76 \%)$, witnessing human distress $(64 \%)$, insufficient possibilities to intervene (51\%) and the sight of dead and wounded people (50\%). Shootings directed at oneself and rejection by the local population were reported by more than one-third of the veterans.

\section{[ TABLE 1 ]}




\section{Positive and negative experiences}

The majority of the peacekeepers judged their deployment period as an experience that broadened their horizon ( $82 \%$; see Table I). More than half of the veterans reported that the deployment period was characterised by comradeship (55\%) and increased their selfconfidence (52\%). One-third of the veterans reported that it was a period which resulted in good friendships. Peacekeepers also judged negatively about the deployment period: $29 \%$ considered the deployment period as a period that was a heavy burden for their home front and $10 \%$ rated the deployment period as a heavy burden for themselves. One-fifth of the peacekeepers reported that they did not yet completely deal with their deployment experience. Compared to the other operations, the Lebanon veterans reported less often that the deployment was a heavy burden for their home front, and that the deployment resulted in good friendships; they more often reported that the deployment period no longer occupied them. This may be associated with the longer timeframe that has passed since the deployment to Lebanon. Compared with the other operations, the peacekeepers of the former Yugoslavia more often reported that the deployment increased their self-confidence, the deployment resulted in good friendships, and that it was a period characterised by comradeship.

\section{PTSD symptomatology}

Table II presents the mean scores of PTSD symptoms. It appeared that peacekeepers who went to Cambodia reported a significantly lower level of PTSD symptoms than veterans from the former Yugoslavia. Veterans from Cambodia also reported significantly lower levels of avoidance symptoms than veterans from the former Yugoslavia and Lebanon.

Veterans from the "Various missions" category reported significantly lower levels of PTSD symptoms than veterans who went to the former Yugoslavia, Lebanon and Cambodia.

According to the DSM-IV rules, 190 veterans $(5.6 \%$; $95 \%$ confidence interval $(\mathrm{CI})=4.8-6.4)$ met the criteria for a PTSD diagnosis as estimated with the SRIP. In addition to meeting all criteria for the diagnosis of PTSD, another $5.7 \%$ of the peacekeepers met two of the three criteria for PTSD (partial PTSD), and 9.8\% met one criterion for PTSD. Those who met one criterion for PTSD predominantly met criterion D (i.e., hyperarousal; 7\%).

Those who met two criteria for PTSD predominantly met either criteria C and D (2.7\%), or criteria B and $\mathrm{D}(2.1 \%)$.

The highest prevalence rates of PTSD were found among veterans who went to the former Yugoslavia (8.0\%; 95\% CI_6.6_9.5) and Lebanon (6.2\%; 95\% CI_4.6_7.8).

Almost $4 \%$ of the veterans who went to Cambodia had PTSD $(3 . \overline{7} \% ; \overline{9} 5 \%$ CI_1.6 5.9) and $2 \%(95 \%$ CI_1.1_2.9) of the veterans of the "Various missions" had PTSD $\left(\chi^{2}=38.2 ; \overline{\mathrm{df}}=\overline{3}, \rho<0.0001\right)$.

\section{[ TABLE 2 ]}

\section{Help-seeking behaviour during deployment}

Twelve percent $(n=382)$ of the peacekeepers contacted a professional health care worker during their deployment for problems they attributed to their peacekeeping experience.

Significant differences were found between the peacekeeping operations. Compared to Lebanon (9\%), Cambodia (7\%) and the Various missions (8\%), peacekeepers who went to the former Yugoslavia more often used professional help during their deployment $\left(17 \% ; \chi^{2}=61.04, \mathrm{df}=3 ; \rho<\right.$ 0.0001 ). Of those who used professional help during deployment, $15 \%$ met the criteria for a current PTSD diagnosis. Among those who did not use professional help during deployment, $4 \%$ met the criteria for PTSD $\left(\chi^{2}=69.91 ; \mathrm{df}=1 ; p<0.0001\right)$.

\section{Factors associated with PTSD symptoms}

The following variables were significantly associated with PTSD symptoms both in the total sample and in each of the three peacekeeping missions: a lower level of education, being single, having experienced more potentially traumatic situations during deployment, having had no control over the situation during deployment, reporting more feelings of powerlessness, and using professional help during deployment (see Table III).

Having the idea that the mission had become meaningless and perceiving the deployment as more threatening was significantly associated with the level of PTSD symptoms in the total sample and 
among veterans who went to the former Yugoslavia or Lebanon, but not among peacekeepers who went to Cambodia. For the total sample, the number of years elapsed since deployment was significantly related to PTSD symptoms (although the $\beta$ coefficient was rather small). This appears to be caused by the Lebanon group, since in this group a higher number of years elapsed since the deployment was significantly associated with a higher level of PTSD symptoms, whereas this was not the case in the other peacekeeping operations.

With respect to the total sample of peacekeepers, receiving professional help during deployment, having finished a lower level of education and feeling more powerless had the highest semi-partial correlations $(0.17,-0.13$ and 0.13 , respectively). This means that these variables made the highest unique contribution to the total variance of current PTSD symptoms. Altogether the regression model accounted for $27 \%$ of the variance in PTSD symptom severity.

\section{DISCUSSION}

The aims of the present study were to examine positive and negative consequences of peacekeeping operations, the PTSD prevalence rates, help-seeking behaviour during deployment, and factors associated with PTSD symptoms among peacekeepers who participated in international peacekeeping operations since 1975. We found an overall PTSD rate of 5.6\% among the peacekeepers, with $8.0 \%$ among veterans who went to the former Yugoslavia and about 4\% among peacekeepers who went to Cambodia. The majority of peacekeepers also reported positive experiences of the deployment. In addition to a higher number of traumatic situations during deployment, we found that a more negative appraisal of the deployment period was significantly associated with PTSD symptoms. Also, having contacted a health care worker during deployment appeared to be a significant predictor for current PTSD symptoms.

\section{[ TABLE 3 ]}

Before discussing the results of this study, some methodological considerations have to be taken into account. Firstly, the data were gathered retrospectively by means of selfreporting.

Therefore, we cannot make causal inferences about the relationships between variables. Secondly, we may express concerns about the representativeness of the study sample. With a response rate of $43 \%$ it is possible that selection has occurred, which may limit the generalizability of the results. Because the former peacekeepers could participate anonymously, no information about the non-responders was available. Therefore, it is not possible to ascertain whether healthy or unhealthy peacekeepers were more likely to respond. Thirdly, it should be noted that the regression equation predicted $27 \%$ of the variance in PTSD severity. Although this percentage is higher than the explained variance found in other studies on PTSD among peacekeepers (Litz et al., 1997; Sutker et al., 1993; Wolfe et al., 1993), it makes clear that other variables not included in the current study are important in accounting for the residual variance. Possible variables could be: predeployment psychopathology, coping strategies, personality characteristics, and social support.

Another concern is that positive and negative consequences of the deployment and the subjective appraisal of the deployment period were measured by self-constructed items. No information on reliability and validity is available. It would be advisable to use well-designed and validated instruments in future research. Finally, in the present study we focused on PTSD. When examining the psychological consequences of exposure to combat related traumatic events, focusing on PTSD is an obvious outcome measure; it's a widely used outcome measure in research on military veterans and previous research has demonstrated that PTSD may be common among war veterans (Bramsen \& Van der Ploeg, 1999a; Engdahl, Dikel, Eberly, \& Blank, 1997; Kulka et al., 1990). However, research has shown that in addition to PTSD other disorders can occur following traumatic events (Boscarino, 1995; Deering, Glover, Ready, Eddleman, \& Alarcon, 1996; Engdahl, Dikel, Eberly, \& Blank, 1998; Shalev et al., 1998). Therefore, including other outcome measures, such as anxiety disorders, adjustment disorder, depression, or substance abuse, will be meaningful if we want to understand the complete picture of psychological adjustment problems following exposure to combat-related events. In contrast to these limitations, the present study has some important strengths. A sample of veterans was approached, including veterans from each branch of military service and both non-treatment- 
seeking and treatment-seeking veterans. Another strength of the study is the large sample size. Because of this we were able to make a comparison between peacekeepers of three different peacekeeping operations. To date, no such large-scale study including peacekeepers of different peacekeeping missions has been performed.

We found an overall PTSD prevalence rate of 5.6\%, ranging between 8.0\% PTSD among peacekeepers who went to the former Yugoslavia and 2.0\% among veterans of the "Various missions" group. These prevalence rates are comparable to the PTSD rates found among American veterans who went to Somalia (8\%; Litz et al., 1997), and Norwegian peacekeepers who went to Lebanon (5\%; Mehlum \& Weisaeth, 2002), but lower than PTSD rates found among American veterans who participated in Operation Desert Storm (19\%; Sutker et al., 1993). The present study also provides knowledge about the potential long-term course of PTSD symptoms, illustrated by the fact that $6 \%$ of the Lebanon veterans reported PTSD even 10-17 years after their deployment. The PTSD rate found among the Dutch Lebanon veterans is very similar to the rate found among Norwegian Lebanon veterans (5\%; Mehlum \& Weisaeth, 2002; Weisaeth, Mehlum, \& Mortensen, 1996). In addition to those meeting all criteria for a PTSD diagnosis, we found that another $5.7 \%$ of the peacekeepers reported partial PTSD (i.e., met two criteria). Previous findings showed that subclinical phenomena as well as PTSD can severely affect quality of life. So, peacekeepers with partial PTSD may also experience serious disruptive effects in their life and may need help.

Consistent with other research we found evidence for a positive relationship between the number of war-zone stressors during deployment and current PTSD symptoms (Bramsen, 1995; Friedman et al., 1994; Sutker et al., 1993). The present study also found additional risk factors for PTSD symptoms among peacekeeping personnel. The results showed that, in addition to the degree of exposure to objective stressful situations, the appraisal of the deployment is also an important factor. This is consistent with the ideas of Lazarus and Folkman who argue that a person's appraisal of what is happening is important as well (Lazarus, 1999). Veterans who felt more powerless and threatened during deployment, who thought they had no control over the situation, or who thought that the mission had become meaningless, reported more current PTSD symptoms. This may also illustrate some unique stressors associated with peacekeeping operations nowadays. A lack of power is considered a major problem in the implementation of UN peacekeeping operations (Liu, 1992).

Peacekeeping personnel are generally outmanned and outgunned by the conflicting parties, and can only use force for self-defense. Therefore, peacekeeping personnel may be unable to prevent hostile actions directed at civilians or at themselves and may be forced to passively witness atrocities (Litz, 1996).

The present study suggests that it is important for peacekeepers to be engaged in meaningful peacekeeping operations and to feel as much as possible in control of the situation during deployment. This result is consistent with a study among United States soldiers participating in the peacekeeping mission to Bosnia, which showed that being engaged in meaningful work during the deployment was strongly associated with deriving benefits from the deployment afterwards (Britt, Adler, \& Bartone, 2001). The present study also demonstrated that in addition to negative consequences of participation in peacekeeping operations, peacekeepers can emerge from missions with positive experiences: more than $80 \%$ of them felt that their peacekeeping experience broadened their horizon, $70 \%$ looked back on the deployment with a good feeling, and more than half reported that the deployment period increased their self-confidence and was characterised by comradeship.

This is consistent with previous studies examining positive consequences of peacekeeping operations (Bache \& Hommelgaard, 1994; Mehlum, 1995). Further research on which factors are associated with more beneficial outcomes of participation in peacekeeping operations appears important.

In the present study it was found that $12 \%$ of the peacekeepers contacted a health care worker during their deployment. Fifteen percent of those receiving professional help during deployment met the criteria for PTSD versus 4\% among those who did not use professional help during deployment. Thus, peacekeepers who did use professional help during deployment were at risk for current PTSD. This finding was also supported by the results of the regression analyses. These results provide useful leads for intervention and prevention programs, and can be used for early identification of peacekeepers at risk for long-term adjustment problems.

Peacekeeping operations can be quite different from each other with respect to duties, experiences, complexity and the degree of danger involved for the peacekeepers. These differences were also 
reflected in the results of the present study, since we found significant differences between the three peacekeeping operations in the reported positive and negative experiences, the degree of exposure during deployment, help-seeking behaviour during deployment and current PTSD rates. Such differences indicate that characteristics typical for each separate peacekeeping mission should be taken into account as well. However, we also found a lot of similarities in the risk factors for PTSD symptoms between the different missions. For instance, the number of stressors during deployment, more feelings of powerlessness during deployment, having had no control over the situation, and receiving professional help during deployment were significantly associated with PTSD symptoms in all three peacekeeping missions. Such factors that prove to be significant risk factors in all three missions may indicate a more general risk factor.

Since new peacekeeping/peace-enforcement operations continue to appear, such as those in Afghanistan and Iraq, and a large number of peacekeeping operations are still ongoing, many peacekeepers from all over the world will be exposed to stressful, dangerous or even life-threatening situations. The present study shows that, although most of the peacekeepers adjusted well, about $6 \%$ met the criteria for a PTSD diagnosis. The results also suggest that early identification of peacekeepers at risk of developing PTSD symptoms after their deployment may benefit from information about the degree of exposure during deployment, the extent to which the peacekeeper felt powerlessness and out of control, or participated in a meaningful peacekeeping operation. In addition, those peacekeepers who contacted health care professionals during deployment may be at risk of adjustment problems following deployment and may benefit from an early help offer. To further unravel risk and protective factors for PTSD symptom severity among peacekeeping personnel, longitudinal studies including pre-deployment measurements and measurements during deployment are needed. Such designs may help us to draw conclusions about the causal relationships between PTSD and potential risk and protective factors, and may increase our knowledge about the longitudinal course of PTSD.

\section{TABLES}

\begin{tabular}{|c|c|c|c|c|c|c|c|c|c|c|c|}
\hline \multirow[t]{2}{*}{$N^{a}$} & \multicolumn{2}{|c|}{ Total 3,481} & \multicolumn{2}{|c|}{ Yugoslavia 1,367} & \multicolumn{2}{|c|}{ Lebanon 883} & \multicolumn{2}{|c|}{ Cambodia 305} & \multicolumn{2}{|c|}{ Various missions 926} & \multirow{2}{*}{$\begin{array}{c}\text { Anova }(\mathrm{df}=3) \\
F\end{array}$} \\
\hline & M & $\mathrm{SD}$ & M & $\mathrm{SD}$ & M & $\mathrm{SD}$ & M & $\mathrm{SD}$ & M & $\mathrm{SD}$ & \\
\hline \multicolumn{12}{|l|}{ Exposure-related variables } \\
\hline Number of stressors during deployment ${ }^{\mathrm{b}}$ & 4.4 & 3.0 & 5.1 & 2.6 & 5.3 & 2.8 & 6.1 & 2.3 & 1.8 & 2.3 & $450.6^{\star \star \star}$ \\
\hline \multicolumn{12}{|l|}{ Appraisal of the deployment } \\
\hline Feelings of powerlessness during deployment ${ }^{c}$ & 3.0 & 1.2 & 3.4 & 1.0 & 3.2 & 1.1 & 3.1 & 1.1 & 2.3 & 1.2 & $196.4^{\star \star \star}$ \\
\hline Evaluating deployment as threatening ${ }^{\mathrm{c}}$ & 2.6 & 0.9 & 2.7 & 0.9 & 2.7 & 0.8 & 2.8 & 0.8 & 2.2 & 0.9 & $66.8^{\star \star \star}$ \\
\hline Having the idea that the mission has become & & & & & & & & & & & \\
\hline meaningless $(\%)$ & $28 \%$ & & $32 \%$ & & $32 \%$ & & $32 \%$ & & $18 \%$ & & $\chi^{2}=70.6^{\star \star \star}$ \\
\hline Having no control over the situation (\%) & $32 \%$ & & $36 \%$ & & $45 \%$ & & $31 \%$ & & $15 \%$ & & $\chi^{2}=206.2^{\star \star \star}$ \\
\hline Having insufficient possibilities to intervene (\%) & $51 \%$ & & $54 \%$ & & $69 \%$ & & $65 \%$ & & $24 \%$ & & $\chi^{2}=403.8^{\star \star \star}$ \\
\hline \multicolumn{12}{|l|}{ Positive and negative experiences of deployment period: } \\
\hline period that no longer occupies me & $13 \%$ & & $9 \%$ & & $18 \%$ & & $6 \%$ & & $15 \%$ & & $\chi^{2}=49.4^{\star \star \star}$ \\
\hline experience that broadened my horizon & $82 \%$ & & $84 \%$ & & $80 \%$ & & $87 \%$ & & $78 \%$ & & $\chi^{2}=21.2^{\star \star \star}$ \\
\hline experience that increased my self-confidence & $52 \%$ & & $61 \%$ & & $47 \%$ & & $50 \%$ & & $43 \%$ & & $\chi^{2}=81.3^{\star \star \star}$ \\
\hline period that resulted in good friendships & $32 \%$ & & $43 \%$ & & $18 \%$ & & $33 \%$ & & $29 \%$ & & $\chi^{2}=155.4^{\star \star \star}$ \\
\hline period characterised by comradeship & $55 \%$ & & $67 \%$ & & $47 \%$ & & $52 \%$ & & $47 \%$ & & $\chi^{2}=126.4^{\star \star \star}$ \\
\hline period looking back on with a good feeling & $70 \%$ & & $76 \%$ & & $65 \%$ & & $66 \%$ & & $66 \%$ & & $\chi^{2}=41.0^{\star \star \star}$ \\
\hline period of heavy burden for the home front & $29 \%$ & & $33 \%$ & & $22 \%$ & & $34 \%$ & & $29 \%$ & & $\chi^{2}=40.2^{\star \star \star}$ \\
\hline period of heavy burden for myself & $10 \%$ & & $12 \%$ & & $10 \%$ & & $13 \%$ & & $6 \%$ & & $\chi^{2}=27.8^{\star \star \star}$ \\
\hline experience not yet completely dealt with & $19 \%$ & & $26 \%$ & & $20 \%$ & & $17 \%$ & & $7 \%$ & & $\chi^{2}=127.5^{\star \star \star}$ \\
\hline experience that did more bad than good & $4 \%$ & & $4 \%$ & & $5 \%$ & & $4 \%$ & & $2 \%$ & & $\chi^{2}=9.8^{\star}$ \\
\hline
\end{tabular}


A.J.E. Dirkzwager, I. Bramsen, H.M. van der Ploeg

Factors associated with posttraumatic stress among peacekeeping soldiers.

Anxiety, Stress and Coping: jrg. 18, 2005, nr. 1, p. 37-51

Table II. Current PTSD symptomatology.

\begin{tabular}{|c|c|c|c|c|c|c|c|c|c|c|c|}
\hline \multirow[t]{2}{*}{$N^{a}$} & \multicolumn{2}{|c|}{ Total 3,481 } & \multicolumn{2}{|c|}{ Yugoslavia 1,367} & \multicolumn{2}{|c|}{ Lebanon 883} & \multicolumn{2}{|c|}{ Cambodia 305} & \multicolumn{2}{|c|}{ Various missions 926} & \multirow{2}{*}{$\begin{array}{c}\text { Anova }(\mathrm{df}=3) \\
F\end{array}$} \\
\hline & M & $\mathrm{SD}$ & M & $\mathrm{SD}$ & M & $\mathrm{SD}$ & M & SD & M & SD & \\
\hline PTSD symptoms & & & & & & & & & & & $\mathrm{F}$ \\
\hline PTSD - Total symptom severity & 28.8 & 9.6 & 30.3 & 10.5 & 29.8 & 10.2 & 27.8 & 8.9 & 25.7 & 6.7 & $46.8^{\star \star \star}$ \\
\hline PTSD - Intrusion & 7.0 & 2.3 & 7.2 & 2.5 & 7.2 & 2.5 & 6.8 & 2.1 & 6.4 & 1.5 & $26.1^{\star \star \star}$ \\
\hline PTSD - Avoidance & 11.9 & 4.4 & 12.6 & 4.9 & 12.2 & 4.7 & 11.2 & 4.0 & 10.5 & 3.1 & $45.4^{\star \star}$ \\
\hline PTSD - Hyperarousal & 9.9 & 3.7 & 10.5 & 4.0 & 10.4 & 3.9 & 9.8 & 3.6 & 8.8 & 2.8 & $42.6^{\star \star \star}$ \\
\hline \multicolumn{12}{|l|}{ PTSD rate } \\
\hline PTSD diagnosis (all three criteria) & $5.6 \%$ & & $8.0 \%$ & & $6.2 \%$ & & $3.7 \%$ & & $2.0 \%$ & & \\
\hline Two criteria for PTSD & $5.7 \%$ & & $7.0 \%$ & & $6.6 \%$ & & $4.7 \%$ & & $3.1 \%$ & & \\
\hline One criterion for PTSD & $9.8 \%$ & & $11.5 \%$ & & $11.8 \%$ & & $6.8 \%$ & & $6.2 \%$ & & \\
\hline
\end{tabular}

${ }^{\star} p<0.01 ;{ }^{\star \star} p<0.001 ;{ }^{\star \star \star} p<0.0001$.

a The total $N$ differed for each analysis due to missing values.

\begin{tabular}{|c|c|c|c|c|c|c|c|c|c|c|c|c|}
\hline \multirow[t]{2}{*}{ Predictor } & \multicolumn{3}{|c|}{$\begin{array}{c}\text { Total } \\
(1975-1996)\end{array}$} & \multicolumn{3}{|c|}{$\begin{array}{c}\text { Former Yugoslavia } \\
\quad(1992-1996)\end{array}$} & \multicolumn{3}{|c|}{$\begin{array}{c}\text { Lebanon } \\
(1979-1986)\end{array}$} & \multicolumn{3}{|c|}{$\begin{array}{c}\text { Cambodia } \\
(1992-1994)\end{array}$} \\
\hline & $r^{b}$ & $\beta$ & $\mathrm{sr}^{\mathrm{c}}$ & $r$ & $\beta$ & sr & $r$ & $\beta$ & $\mathrm{sr}$ & $r$ & $\beta$ & $\mathrm{sr}$ \\
\hline \multicolumn{13}{|l|}{ Demographic and military characteristics } \\
\hline Education & -0.16 & $-0.14^{\star \star \star}$ & -0.13 & -0.20 & $-0.13^{\star \star \star}$ & -0.13 & -0.19 & $-0.15^{\star \star \star}$ & -0.14 & -0.22 & $-0.14^{\star}$ & -0.12 \\
\hline Marital status: single & 0.12 & $0.11 \star \star \star \star$ & 0.10 & 0.02 & $0.06^{\star}$ & 0.06 & 0.21 & $0.18^{\star \star \star}$ & 0.18 & 0.18 & $0.20^{\star \star \star}$ & 0.19 \\
\hline Mean age & -0.07 & -0.03 & -0.02 & -0.06 & -0.05 & -0.04 & -0.07 & -0.03 & -0.03 & 0.06 & 0.05 & 0.03 \\
\hline Military rank & -0.11 & 0.00 & 0.00 & -0.05 & 0.01 & 0.01 & -0.10 & -0.02 & -0.02 & -0.03 & 0.02 & 0.02 \\
\hline Years elapsed since deployment & 0.03 & $0.06^{\star \star}$ & 0.06 & 0.01 & -0.02 & -0.01 & 0.07 & $0.07^{\star}$ & 0.07 & -0.07 & -0.01 & -0.01 \\
\hline \multicolumn{13}{|l|}{ Exposure } \\
\hline Number of stressors during deployment & 0.35 & $0.15^{\star \star \star}$ & 0.12 & 0.32 & $0.16^{\star \star \star}$ & 0.13 & 0.28 & $0.12^{\star \star}$ & 0.10 & 0.29 & $0.24^{\star \star}$ & 0.21 \\
\hline \multicolumn{13}{|l|}{ Appraisal of deployment } \\
\hline Insufficient possibilities to intervene & 0.27 & -0.01 & -0.01 & 0.22 & -0.02 & -0.02 & 0.22 & 0.02 & 0.01 & 0.21 & 0.01 & 0.01 \\
\hline Having no control over the situation & 0.28 & $0.09^{\star \star \star}$ & 0.08 & 0.24 & $0.10^{\star \star}$ & 0.08 & 0.27 & $0.07^{\star}$ & 0.06 & 0.25 & $0.12^{\star}$ & 0.11 \\
\hline Idea mission has become meaningless & 0.25 & $0.11^{\star \star \star}$ & 0.10 & 0.24 & $0.13^{\star \star \star}$ & 0.12 & 0.26 & $0.13^{\star \star \star}$ & 0.12 & 0.13 & 0.04 & 0.03 \\
\hline Evaluating deployment as threatening & 0.30 & $0.09^{\star \star \star}$ & 0.08 & 0.29 & $0.09^{\star \star}$ & 0.08 & 0.29 & $0.11^{\star \star}$ & 0.09 & 0.25 & 0.05 & 0.04 \\
\hline More feelings of powerlessness & 0.37 & $0.16^{\star \star \star}$ & 0.13 & 0.32 & $0.15^{\star \star \star}$ & 0.13 & 0.35 & $0.13^{\star \star}$ & 0.10 & 0.31 & $0.21^{\star \star}$ & 0.17 \\
\hline Professional help during deployment & 0.25 & $0.18^{\star \star \star}$ & 0.17 & 0.27 & $0.19^{\star \star \star}$ & 0.19 & 0.24 & $0.14^{\star \star \star}$ & 0.14 & 0.26 & $0.24^{\star \star \star}$ & 0.24 \\
\hline$R^{2}$ & & 0.27 & & & 0.26 & & & 0.28 & & & 0.31 & \\
\hline
\end{tabular}

a The distribution of the dependent variable "PTSD symptom severity" was positively skewed and had positive kurtosis. Therefore, we transformed this variable with a $\log$-transformation. The regression analyses with the transformed and non-transformed dependent variable resulted in identical significant results. $\mathrm{b}_{r}=$ Pearson correlation.

$\mathrm{c}_{\mathrm{sr}}=$ semipartial correlation.

${ }^{\star} p<0.05 ;{ }^{\star \star} p<0.01 ;{ }^{\star \star \star} p<0.001$.

\section{REFERENCES}

American Psychiatric Association (1994). Diagnostic and statistical manual of mental disorders (4th edition). Washington, DC: American Psychiatric Association.

Bache, M., \& Hommelgaard, B. (1994). Danish UN Soldiers. Experiences and stress reactions . Copenhagen: Defence Centre for Leadership.

Boscarino, J. A. (1995). Posttraumatic stress and associated disorders among Vietnam veterans: The significance of combat exposure and social support. Journal of Traumatic Stress , 8(2), $317 \_/ 336$.

Bramsen, I. (1995). The long-term psychological adjustment of World War II survivors in the Netherlands . Delft: Eburon Press.

Bramsen, I., Dirkzwager, A. J. E., Van Esch, S. C. M., \& Van der Ploeg, H. M. (2001). Consistency of self-reports of traumatic events in a population of Dutch peacekeepers: Reason for optimism? Journal of Traumatic Stress , 14(4), 733_/740.

Bramsen, I., \& Van der Ploeg, H. M. (1999a). Fifty years later: The long-term psychological adjustment of aging World War II survivors. Acta Psychiatrica Scandinavica , 100, 350_/358.

Bramsen, I., \& Van der Ploeg, H. M. (1999b). Use of medical and mental health care by World War II survivors in the Netherlands. Journal of Traumatic Stress, 12(2), 243_/261.

Britt, T. W., Adler, A. B., \& Bartone, P. T. (2001). Deriving benefits from stressful events: The role of engagement in meaningful work and hardiness. Journal of Occupational Health Psychology, $6(1), 53 / 63$.

Clipp, E. C., \& Elder, G. H. Jr. (1996). The aging veteran of World War II: Psychiatric and life course insights. In P. E. Ruskin, \& J. A. Talbott (Eds.), Aging and posttraumatic stress disorder (pp. 19_/51). Washington: American Psychiatric Press, Inc. 
Deering, C. G., Glover, S. G., Ready, D., Eddleman, H. C., \& Alarcon, R. D. (1996). Unique patterns of comorbidity in posttraumatic stress disorder from different sources of trauma. Comprehensive Psychiatry, 37, 336_/346.

Engdahl, B., Dikel, T. N., Eberly, R., \& Blank, A. (1997). Posttraumatic stress disorder in a community group of former prisoners of war: Normative response to severe trauma. American Journal of Psychiatry, 154(11), 1576_/ 1580.

Engdahl, B., Dikel, T. N., Eberly, R., \& Blank, A. (1998). Comorbidity and course of psychiatric disorders in a community sample of former prisoners of war. American Journal of Psychiatry, 155(12), 1740_11745.

Folkman, S., Lazarus, R. S., Dunkel-Schetter, C., Delongis, A., \& Gruen, R. J. (1986). Dynamics of a stressful encounter: Cognitive appraisal, coping, and encounter outcomes. Journal of Personality and Social Psychology, 50(5), 992_/1003.

Friedman, M. J., Schnurr, P. P., \& McDonagh-Coyle, A. (1994). Post-traumatic stress disorder in the military veteran. Psychiatric Clinics of North America, 17(2), 265 /277.

Green, B. L., Grace, M. C., Lindy, J. D., Gleser, G. C., \& Leonard, A. (1990). Risk factors for PTSD and other diagnoses in a general sample of Vietnam veterans. American Journal of Psychiatry, 147(6), 729_/733.

Hovens, J. E., Bramsen, I., \& Van der Ploeg, H. M. (2000). Zelfinventarisatielijst Posttraumatische Stressstoornis (ZIL): Handleiding. [Self-Rating Inventory for PTSD: Manual.] . Lisse, The Netherlands: Swets \& Zeitlinger.

Hovens, J. E., Van der Ploeg, H. M., Bramsen, I., Klaarenbeek, M. T. A., Schreuder, J. N., \& Rivero, V. V. (1994). The development of the Self-Rating Inventory for Posttraumatic Stress Disorder. Acta Psychiatrica Scandinavica, 90, 172_/183.

Kettner, B. (1972). Combat strain and subsequent mental health. Acta Psychiatrica Scandinavica, Suppl. 230.

Kulka, R. A., Schlenger,W. E., Fairbank, J. A., Hough, R. L., Jordan, B. K., Marmar, C. R., \&Weiss, D. S. (1990). Trauma and the Vietnam war generation. Report of findings from the National Vietnam Veterans Readjustment Study. New York: Brunner/Mazel, Publishers.

Lazarus, R. S. (1999). Stress and emotion: A new synthesis . New York: Springer Publishing Company.

Litz, B. T. (1996). The psychological demands of peacekeeping for military personnel. Clinical Quarterly, 6(1), 1_/8.

Litz, B. T., Orsillo, S. M., Friedman, M., Ehlich, P., \& Batres, A. (1997). Posttraumatic stress disorder associated with peacekeeping duty in Somalia for U.S. military personnel. American Journal of Psychiatry, 154(2), 178_/ 184.

Liu, F. T. (1992). United Nations peacekeeping and the non-use of force . Boulder \& London: Lynne Riener Publishers, Inc.

MacDonald, C., Chamberlain, K., Long, N., \&Mirfin, K. (1996). Psychological effects of peacekeeping deployments on military personnel. Palmerston North: Massey University, Department of Psychology.

Mehlum, L. (1995). Positive and negative consequences of serving in a UN peacekeeping mission. A follow-up study. International Review of Armed Forces Medical Services , 68, 289_/295.

Mehlum, L., \& Weisaeth, L. (2002). Predictors of posttraumatic stress reactions in Norwegian UN peacekeepers 7 years after service. Journal of Traumatic Stress , 15(1), 17_/26.

Shalev, A. Y., Freedman, S., Peri, T., Brandes, D., Sahar, T., Orr, S. P., \& Pitman, R. K. (1998). Prospective study of posttraumatic stress disorder and depression following trauma. American Journal of Psychiatry, 155(5), 630_/ 637.

Solomon, Z., Mikulincer, M., \& Avitzur, E. (1988). Coping, locus of control, social support, and combatrelated posttraumatic stress disorder: A prospective study. Journal of Personality and Social Psychology, 55(2), 279_/285.

Solomon, Z., Mikulincer, M., \& Flum, H. (1988). Negative life events, coping responses and combat related psychopathology: A prospective study. Journal of Abnormal Psychology, 97(3), 302_/307.

Sutker, P. B., Uddo, M., Brailey, K., \& Allain, A. N. (1993). War-zone trauma and stress related symptoms in Operation Desert Shield/ Storm (ODS) returnees. Journal of Social Issues , 49(4), 33_150.

Updegraff, J. A., \& Taylor, S. E. (2000). From vulnerability to growth: Positive and negative effects of stressful life events. In J. H. Harvey, \& E. D. Miller (Eds.), Loss and trauma: General and close relationship perspectives (pp. 3_/ 28). Philadelphia, PA: Brunner-Routledge. 
Ward, W. (1997). Psychiatric morbidity in Australian veterans of the United Nations peacekeeping force in Somalia. Australian \& New Zealand Journal of Psychiatry, 31(2), 184_/193.

Weisaeth, L., Mehlum, L., \& Mortensen, M. S. (1996). Peacekeeper stress: New and different? NPC Clinical Quarterly , 6(1), 12_/15.

Wolfe, J., Brown, P. J., \& Kelley, J. M. (1993). Reassessing war stress: Exposure and the Persian Gulf War. Journal of Social Issues , 49(4), $15 / 31$.

Zatzick, D. F., Marmar, C. R., Weiss, D. S., Browner, W. S., Metzler, T. J., Golding, J. M., Stewart, A., Schlenger, W. E., \& Wells, K. B. (1997). Posttraumatic stress disorder and functioning and quality of life outcomes in a nationally representative sample of male Vietnam veterans. American Journal of Psychiatry, 154(12), 1690_/ 1695. 